\title{
Astronomia diurna: medida da abertura angular do Sol e da latitude local
}

\author{
Daytime astronomy: measure of the Sun's angular aperture and local latitude \\ Ivan Ferreira da Costa $^{1}$, Armando de Mendonça Maroja*1 \\ ${ }^{1}$ Universidade de Brasília, Campus de Planaltina, Planaltina, DF, Brasil
}

Recebido em 14 de Dezembro, 2016. Revisado em 29 de Maio, 2017. Aceito em 30 de Maio, 2017

\begin{abstract}
O ensino de astronomia na educação básica, especialmente para crianças do ensino fundamental, apresenta desafios que vão além da formação dos professores e da disponibilidade de equipamentos. Uma dificuldade está no fato das atividades ocorrerem predominantemente no período diurno, o que impõe limitações para atividades de observação astronômica. No entanto, a observação do Sol abre possibilidades de experimentação diurna que permite o estudo de conceitos importantes relativos a astronomia e a geometria. De forma geral essa atividade proporciona também a compreensão do movimento de outros astros sobre a esfera celeste. O objetivo principal desse trabalho é apresentar recursos didáticos para o ensino de astronomia. O público alvo são os formadores de professores da educação básica, especialmente dos cursos de ciências naturais, matemática e física. Mostramos algumas metodologias de baixo custo para realizar análises do movimento do Sol a partir de fotografias ou de medidas diretas da imagem do Sol projetada por um pequeno espelho. Através da análise do movimento do Sol no céu são obtidas grandezas de interesse para astronomia como a abertura angular do Sol e a latitude local. Os resultados dessas medidas concordam com dados disponíveis na literatura.

Palavras-chave: ensino de ciências e matemática, astronomia diurna, abertura angular do Sol, medida da latitude.
\end{abstract}

The astronomy study in basic education, especially for elementary school children, presents challenges that go beyond the training of teachers and the availability of equipment. One difficulty lies in the fact that activities occur predominantly in the daytime period, which imposes limitations on astronomical observation activities. However, the observation of the Sun creates possibilities for daytime experimentation that allows the study of important concepts related to astronomy and geometry. In general, this activity also provides an understanding of the movement of other stars on the celestial sphere. The main objective of this work is to present didactic resources for astronomy teaching. The target audience are the professors of teachers, especially in the areas of natural sciences, mathematics and physics. This article shows some low cost methodologies to perform analyzes of the movement of the Sun, from photographs or direct measurements of the image of the Sun projected by a small mirror. Through the analysis of the movement of the Sun in the sky we obtained results of interest for astronomy like the angular aperture of the Sun and the local latitude. The results of these measures agree with data available in the literature.

Keywords: science and mathematics teaching, daytime astronomy, angular aperture of the Sun, latitude measurement.

\section{Introdução}

Os assuntos referentes ao tema astronomia além de serem interdisciplinares, chamam a atenção da maioria das pessoas de qualquer faixa etária, mas em especial dos jovens. Especular sobre os enigmas da vida e do universo é parte das preocupações presentes entre os jovens no fim do ensino fundamental, como mostram pesquisas que seguem as diretrizes estabelecidas no projeto ROSE (Relevance of Science Education) realizadas por pesquisadores do Brasil e de diversos países da Europa [1].

Respondendo a esse interesse, é importante propiciar aos jovens uma visão cosmológica das ciências que lhes permitam se situarem na escala de tempo do universo,

*Endereço de correspondência: amaroja@unb.br apresentando-lhes os instrumentos para acompanhar e admirar, por exemplo, as conquistas espaciais, as notícias sobre as novas descobertas do telescópio espacial Hubble e a detecção de ondas gravitacionais. Que lhes permitam ainda indagar sobre a origem do universo ou do mundo fascinante das estrelas e as condições para a existência da vida, ou responder perguntas simples como: "Por que ocorrem as estações do ano?" e "Como caminhar orientado pelas estrelas?" [1][2].

O tema astronomia está presente no cotidiano das pessoas, são inúmeros os clubes de astronomia, reportagens sobre astronomia nos veículos de comunicação e nas redes sociais. É tema de destaque nos museus e planetários são estruturas de apoio cultural presente nas principais cidades do Brasil e do mundo. Como destacam Langhi e 
Nardi [3], a astronomia é uma ciência onde o ensino tem dois diferenciais básicos: (i) o grande potencial de apoio por parte das comunidades de astrônomos profissionais e amadores, que devem ser convidados a participar ativamente de atividades de popularização da astronomia nas escolas; (ii) a astronomia possui um grau altamente motivador, uma vez que seu laboratório natural, o céu, está à disposição de todos.

Apesar do interesse dos jovens, o ensino de astronomia tem obstáculos a serem superados. A formação dos professores [2][3][4], livros didáticos que abordem pelo menos os conteúdos previstos nos PCN (Parâmetros Curriculares Nacionais) [2][5][6] e a disponibilidade de recursos didáticos nas escolas ilustram parte desses obstáculos.

O tema astronomia tem destaque no PCN do Ensino Fundamental [5], onde o eixo temático Terra e Universo prevê um estudo aprofundado e amplo, contemplando desde temas da astronomia clássica até as grandes teorias de evolução do universo como, por exemplo, a do "BigBang". Aliás, o previsto no PCN está bem à frente do que é efetivamente ensinado ao longo da formação dos estudantes na educação básica e mesmo na formação dos professores de ciências que atuam no ensino fundamental $[2][4]$.

Não podemos deixar de destacar as iniciativas da Agência Espacial Brasileira (AEB) através da AEBescola na promoção da formação, divulgação e popularização da astronomia no Brasil [7].

\subsection{Observação do Sol como recurso didático em astronomia}

Uma estratégia para superar as dificuldades acima destacadas é disponibilizar para os professores de ciências da educação básica recursos didáticos de baixo custo a fim de aprimorar a formação de estudantes [8]. Nem todas as escolas têm disponibilidade de telescópios e outros recursos didáticos como bússolas, planisférios, esferas armilares e espectroscópios para apoiar as atividades de ensino. Outra dificuldade ocorre na realização de atividades de observação do céu, dado que na maioria das escolas as atividades da segunda etapa do ensino fundamental, fase prevista para o ensino de astronomia, ocorrem no período diurno.

O relógio de Sol com interação humana [9] ou relógio de Sol analêmico é uma atividade interdisciplinar lúdica que difunde conceitos básicos de astronomia e matemática desde as séries iniciais do ensino fundamental. A escala das horas na forma de uma elipse é riscada no pátio da escola utilizando um gabarito. O ponteiro das horas é definido pela sombra de um gnomo, dramatizado por um estudante, que fica em pé em um ponto pré-definido ao longo do eixo da elipse, conforme a época do ano. Os autores da proposta destacam que o relógio é um recurso pedagógico que motiva o estudante a participar das aulas, aumenta sua interação e curiosidade sobre o assunto abordado e o coloca como protagonista do processo de ensino-aprendizagem.

A medida da latitude geográfica local pela posição do Sol pode ser realizada a partir do seguinte procedimento [10]: a sombra de uma haste vertical é medida em vários momentos do dia. A partir de três medidas realizadas em um mesmo dia e espaçadas de 1h30min pode-se determinar a latitude local com incerteza de $6 \%$. Além de uma planilha para cálculo da latitude o autor disponibiliza no anexo do trabalho um roteiro para realização desta atividade pedagógica, que se constitui em uma iniciativa importante que motiva a utilização efetiva da atividade em sala de aula.

Outra proposta interessante é apresentada por Silveira [11] para observação de eclipses solares e explicar por que manchas luminosas "arredondadas" aparecem em uma calçada embaixo das árvores. O princípio físico que explica esse fenômeno é o da câmara escura, as manchas arredondadas correspondem a imagens do Sol, produzidas quando a luz atravessa pequenos orifícios entre as folhas. A mesma estratégia é utilizada na observação de eclipses do Sol, sem riscos para saúde do olho. Um pequeno espelho plano, que faz o papel de orifício, projeta uma imagem nítida do eclipse em uma parede distante (a condição para tal é que a distância à parede deve ser muito maior do que as dimensões do espelho).

Também existem várias iniciativas de produção de materiais didáticos para uso no ensino de astronomia: um modelo para o movimento anual do Sol a partir de uma perspectiva geocêntrica [12], um mini planetário [13], uma esfera celeste didática [14], softwares para simulação dinâmica do sistema solar [15] e uma grande variedade de experimentos que podem ser utilizados em oficinas de astronomia [8][16].

As atividades experimentais mostradas nesse artigo requerem a observação diurna do céu. São atividades de campo que exigem a participação ativa dos grupos de estudantes. As medidas relativas ao movimento do Sol são realizadas através da projeção de sua imagem por um pequeno espelho em uma parede distante. Conceitos de ótica geométrica e matemática são aliados na determinação de grandezas de interesse na astronomia, como a medida da abertura angular do Sol, o cálculo do diâmetro do Sol e a medida da latitude geográfica local.

\section{Referencial teórico}

\subsection{A esfera celeste}

O movimento dos astros no céu aguça a imaginação humana desde a antiguidade. Visto a partir de um referencial fixo em um ponto da superfície da Terra, dizemos que os astros se movimentam sobre uma esfera imaginária, denominada de esfera celeste, de raio arbitrário, na qual estão projetados todos os corpos celestes [17]. Os astros descrevem no céu arcos paralelos ao Equador, nascendo próximos da direção leste e se pondo próximos ao oeste. 
Já para um observador no referencial do Sistema Solar esse movimento é consequência do movimento de rotação da Terra.

A Figura 1a ilustra a trajetória de uma estrela vista por um observador que olha para o céu no hemisfério sul. Ao longo da noite a estrela gira em torno do polo sul celeste (PS). Observe que o plano de órbita da estrela é paralelo ao plano do equador. O PS está inclinado em relação ao plano do horizonte, direção norte-sul, de um ângulo igual à latitude local $(\phi)$. Na figura o horizonte do observador representa o plano tangente à superfície da Terra no local da observação, o zênite (Z) é o ponto no qual a vertical intercepta a esfera celeste acima do observador e o PS e o ponto em que o prolongamento do eixo de rotação da Terra intercepta a esfera celeste no hemisfério sul [17].

O gráfico em destaque no canto inferior direito da Figura 1a mostra que a inclinação do plano de órbita da estrela em relação ao zênite é também igual à latitude local $\phi$.

A Figura 1b apresenta uma montagem fotográfica do rastro de estrelas registrado no delta do Okavango, em Botsuana [18]. Observe que o PS está próximo do horizonte. Isso se deve a latitude local de $-19,3^{\circ}$. Nesse artigo usaremos latitudes negativas para o hemisfério sul e positivas para o hemisfério norte.

Esse movimento complexo pode ser mais bem compreendido utilizando o chamado sistema de coordenadas horizontal [17]. Nesse sistema é usada a posição do observador como centro da esfera celeste (Figura 2), que corresponde ao hemisfério acima do horizonte. As duas coordenadas que definem a posição do astro no céu são o azimute $A$ e a altura $a$.

A altura $a$ corresponde ao ângulo entre o astro e o horizonte do observador, Figura 2. Para astros visíveis esse ângulo está entre $0^{\circ}$ e $90^{\circ}$. Para astros abaixo da linha do horizonte a altura é negativa, variando entre $0^{\circ}$

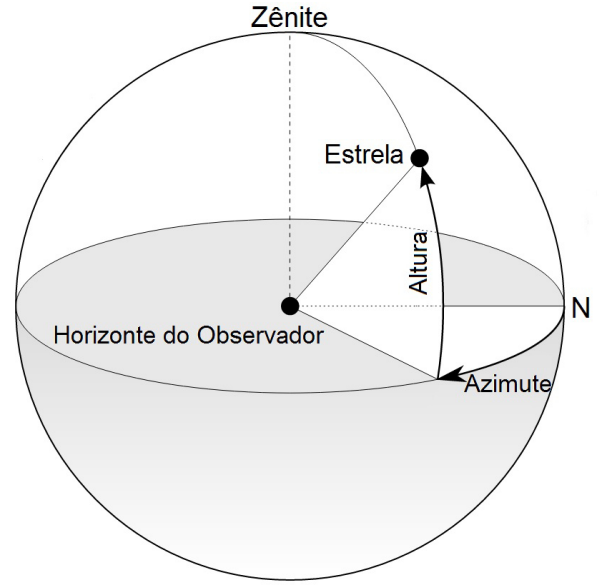

Figura 2: Sistema de coordenadas horizontal. Adaptada de [19].

e $-90^{\circ}$. Já o Azimute $A$ corresponde ao ângulo que o astro perfaz ao redor do horizonte, medido a partir do norte e crescendo para leste. Esse ângulo assume valores entre $0^{\circ}$ e $360^{\circ}$.

\subsection{O movimento diurno do Sol no céu}

O movimento do Sol na esfera celeste durante um dia é análogo ao realizado por uma estrela durante a noite. Como para os demais astros, os arcos que descrevem a trajetória do Sol no céu também são paralelos ao Equador, nascendo próximos da direção leste e se pondo próximos ao oeste, Figura 3.

De forma geral, a posição do Sol no céu depende da hora e do dia do ano, além da posição do observador na Terra. Com o passar dos meses o plano da trajetória do Sol se move no horizonte, fazendo com que a posição do poente (e do nascente) varie ao longo do ano. Isto se deve à inclinação do eixo de rotação da Terra de $23,5^{\circ}$ em relação ao plano da órbita da Terra em torno
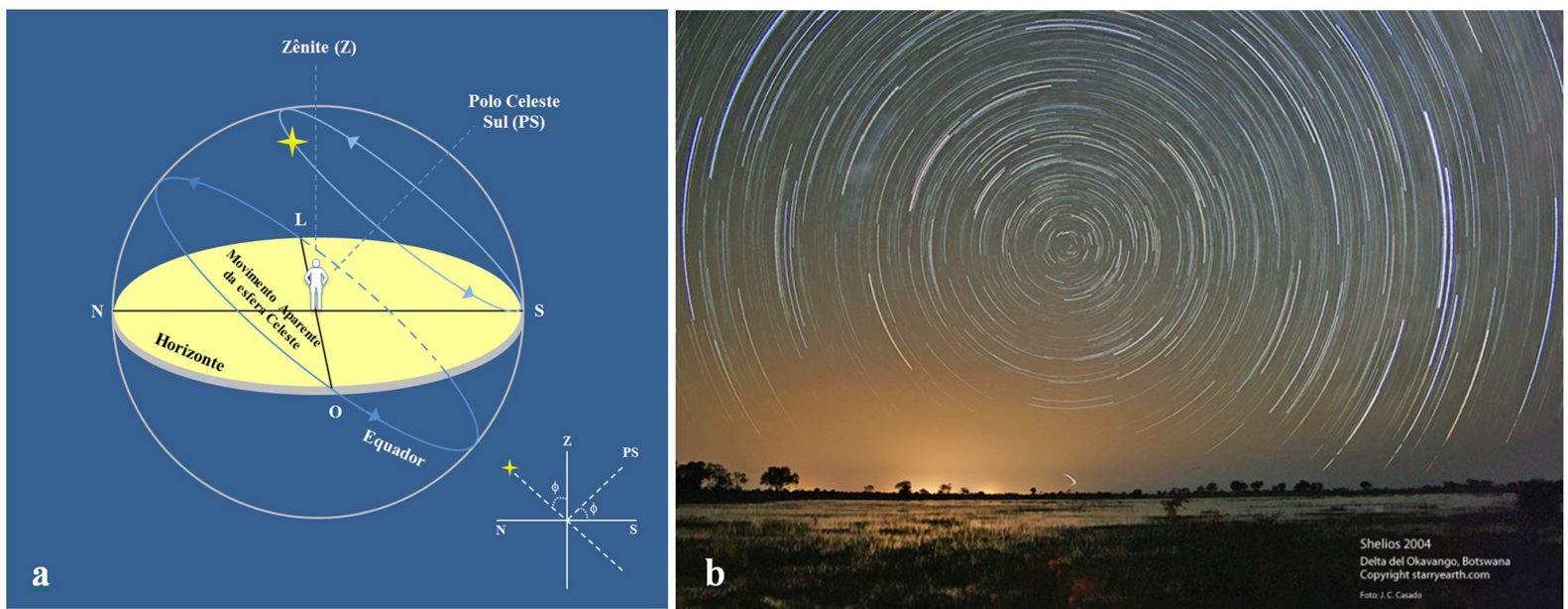

Figura 1: (a) Trajetória de uma estrela sobre a esfera celeste. O detalhe mostra que a inclinação do plano de órbita da estrela em relação ao zênite é igual à latitude local $\phi$. Baseada em Kepler [17]. (b) Rastro de estrelas no céu no delta do Okavango, em Botsuana [18], latitude de $-19,3^{\circ}$. 


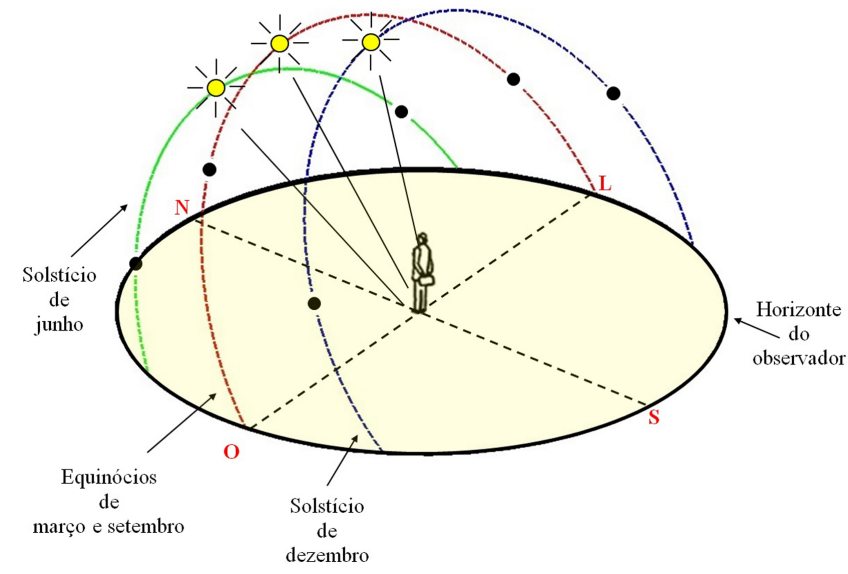

Figura 3: Variação da posição do plano da trajetória do Sol no céu ao longo do ano para um observador no hemisfério sul.

do Sol, plano da eclíptica, Figura 3. Apesar disso, para uma mesma latitude, a inclinação deste plano em relação ao horizonte do observador não varia ao longo do ano, permanecendo paralela ao equador. A inclinação do plano da órbita do Sol em relação à vertical em qualquer época do ano corresponde à latitude do observador $\phi$, como será demonstrado a seguir.

É possível calcular a posição do Sol no céu ao longo do ano, ou seja, o azimute $A$ e a altura $a$ como função do tempo. A trigonometria esférica pode ser utilizada para estudar a trajetória dos astros sobre a esfera celeste sem se preocupar com sua distância à Terra. Utilizando a trigonometria esférica a altura e o azimute do Sol são definidos como [20]:

$$
a=\operatorname{arcsen}[\cos (h) \cos (\delta) \cos (\phi)+\operatorname{sen}(\delta) \sin (\phi)]
$$

e

$$
A=\arccos [(\operatorname{sen}(\delta)-\operatorname{sen}(a) \operatorname{sen}(\phi)) /(\cos (a) \cos (\phi))] .
$$

Onde $\phi$ é a latitude do observador e $h$ é o ângulo da hora solar, que varia de $-180^{\circ}$ a $180^{\circ}$ em um dia, correspondendo à variação de $0 \mathrm{~h}$ a $24 \mathrm{~h}$. A variável $\delta$ é a declinação definida pelo ângulo entre os raios do Sol e o plano equatorial da Terra, sendo $\delta=0^{\circ}$ para os equinócios e $\delta= \pm 23,5^{\circ}$ para os solstícios. Uma aproximaçã $\mathrm{d}^{1} \mathrm{su}-$ ficientemente precisa para nossos objetivos é considerar uma dependência senoidal para a declinação em função do dia do ano. Então podemos escrever

$$
\delta=-23,5^{\circ} \cos (N+10)
$$

onde $N$ é o número de dias decorridos desde $1^{\circ}$ de janeiro.

Na Figura 4 os planos da trajetória do Sol mostrados na Figura 3 relativos aos solstícios e aos equinócios são

\footnotetext{
1 Essa aproximação considera a órbita solar como um círculo e o seno de um ângulo menor do que $23,5^{\circ}$ como o próprio ângulo em radianos, ou seja, sen $(0,410)=0,399 \cong 0,410$. Também considera que o Sol varre um grau por dia (um ano é formado por 12 meses de 30 dias).
}

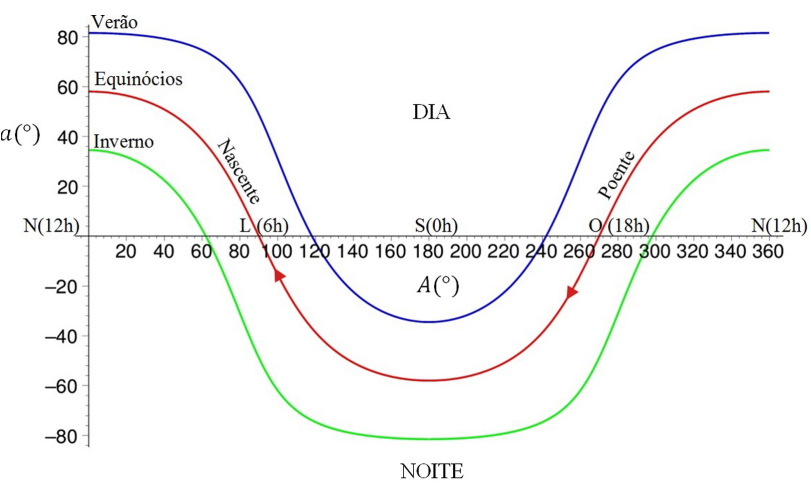

Figura 4: Variação da altura como função do azimute ao longo do dia para um observador na latitude $\phi=-32^{\circ}$, extremo sul do Brasil.

sobrepostos em um único gráfico. As trajetórias foram determinadas a partir das Equações 1 e 2 . A altura $a$ foi colocada no eixo vertical e o azimute $A$ no eixo horizontal. A figura apresenta tanto a trajetória relativa ao período diurno $(a>0)$ como a trajetória relativa ao período noturno $(a<0)$. Acima da escala de variação do azimute, para melhor compreensão do gráfico, são apresentados os pontos cardeais e uma referência horária que permite estabelecer a hora local aproximada.

O observador foi localizado no extremo sul do Brasil (latitude $\phi=-32^{\circ}$ ). A linha vermelha representa a trajetória do Sol na época dos equinócios, $\delta=0^{\circ}$. Analisando a Figura 4 é possível ver que nessa época do ano o Sol nasce exatamente na direção leste $\left(A=90^{\circ}\right)$ e se põe na direção oeste $\left(A=270^{\circ}\right)$.

A linha verde destaca a trajetória do Sol no solstício de inverno, $\delta=23,5^{\circ}$. Já a linha azul representa a trajetória no solstício de verão, $\delta=-23,5^{\circ}$. Observa-se que no inverno o Sol nasce aproximadamente a norte do leste e no verão aproximadamente a sul do leste, já que estamos no hemisfério sul. Ao contrário dos equinócios, quando a noite e o dia têm a mesma duração, é evidente que no verão os dias são mais longos e no inverno as noites são mais longas, bastando observar a porção da órbita acima e abaixo do eixo das abscissas. Essas linhas definem os limites para as trajetórias do Sol ao longo do ano, e a posição do Sol para outras épocas do ano podem ser calculadas utilizando outros valores da declinação. Para outras posições do observador no globo terrestre basta ajustar a latitude $\phi$.

Na Figura 5a as órbitas apresentadas na Figura 4 estão projetadas sobre a esfera celeste. A inclinação da órbita do Sol com a vertical não é sempre igual ao módulo da latitude local, mas a projeção do movimento do Sol no plano vertical ao horizonte do observador e paralelo a direção norte-sul mostra uma trajetória retilínea onde a inclinação com a vertical é precisamente igual ao módulo da latitude local $\phi$, Figura 5b. Observa-se que nesse plano, em qualquer dia, em qualquer época do ano, a inclinação da trajetória com a vertical (zênite) é precisamente igual a $-32^{\circ}$, valor para o nosso exem- 

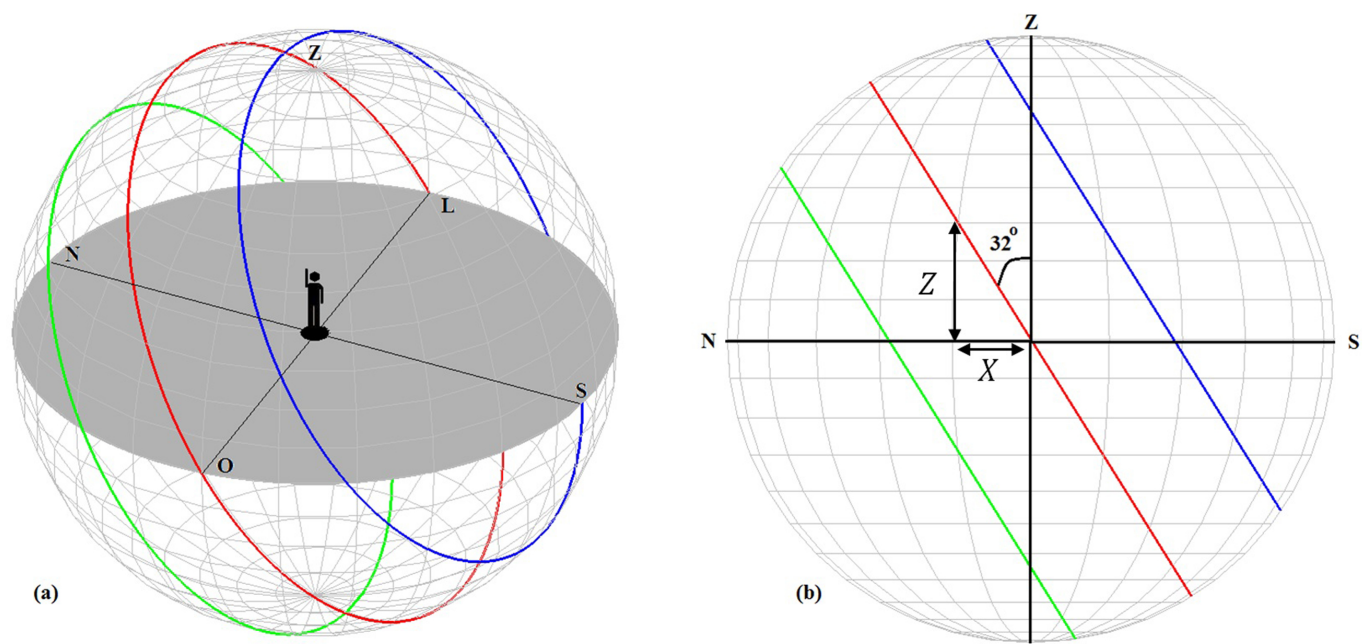

Figura 5: (a) Variação da posição do plano da trajetória do Sol no céu ao longo do ano para um observador no hemisfério sul em um local onde a latitude $\phi=-32^{\circ}$. A curva vermelha corresponde aos equinócios e as curvas verde e azul ao solstício de inverno e de verão respectivamente. (b) Projeção das órbitas no plano vertical ao horizonte do observador e paralelo a direção norte-sul.

plo. Esse resultado, mostrado graficamente na Figura 5b, também pode ser determinado a partir das Equações 1 e 2 conforme mostra o apêndice 1 .

\section{Análise de fotografias do movimento diurno do Sol no céu}

Um dos objetivos desse trabalho é estabelecer um procedimento que permita a medida da latitude local a partir da análise de imagens da trajetória do Sol.

\subsection{Observando na direçao leste-oeste}

A busca na Internet por imagens representativas do movimento do Sol e de outros astros no céu conduz a resultados interessantes. A Figura 6a apresenta o pôr do Sol no parque nacional de Kruger na África do Sul [21], latitude de $-24^{\circ}$, na data de $01 / 08 / 2008$. A trajetória quase vertical apresentada na Figura 6b mostra as fases do eclipse total do Sol ocorrido próximo ao amanhecer em Palu, Indonésia, latitude $-0,54^{\circ}$, em 09/03/2016 [22]. Já a Figura 6c mostra uma sobreposição de fotografias do pôr do Sol sobre o reservatório Gabriel e Galán na Espanha em 2002 [23], latitude de 40 . Na Figura $6 \mathrm{~d}$ é apresentada uma sequência que mostra o pôr da Lua sobre a cidade de Oslo na Noruega [24], latitude de $60^{\circ}$, em 20/04/2015. A fotografia mostra a montagem de imagens espaçadas de 10 minutos de 19h45min até $22 \mathrm{~h} 55 \mathrm{~min}$. Conforme o fotógrafo, o vento forte fez com que alguns dos discos lunares e o planeta Vênus ficassem ligeiramente desfocados. Observa-se que o Sol, a Lua e o planeta Vênus descrevem trajetórias retas no céu nessas fotografias.

Com exceção do eclipse total ocorrido em Palu, as outras fotografias foram realizadas ao pôr do Sol/Lua. Nas Figuras 6a e 6b a trajetória está inclinada para o
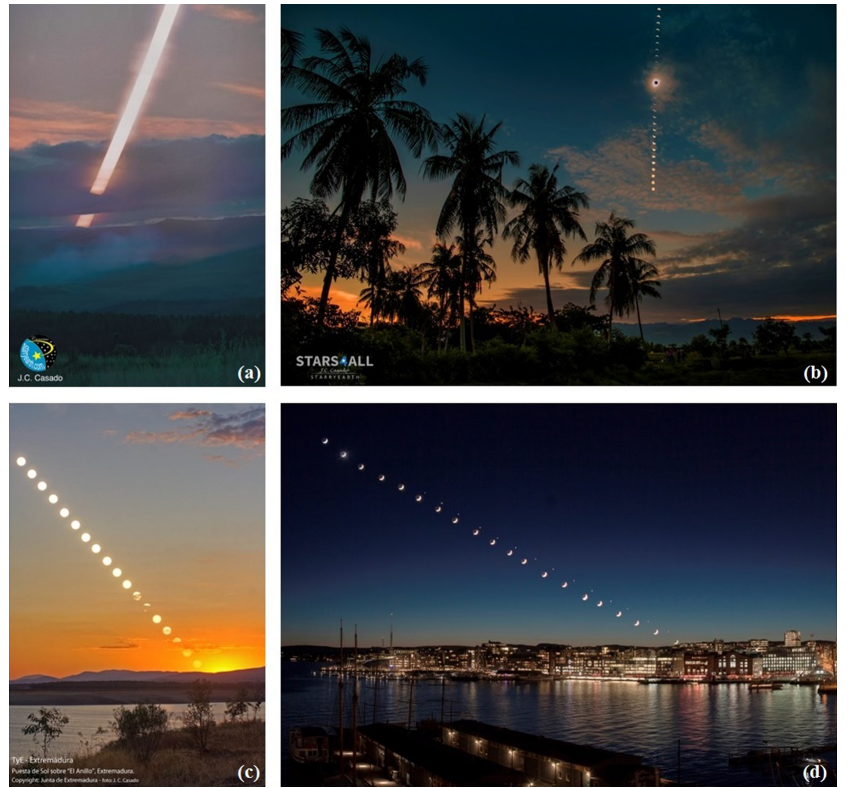

Figura 6: (a) Pôr do Sol no parque nacional de Kruger (África do Sul), latitude de $-24^{\circ}$. (b) Eclipse total do Sol em Palu (Indonésia), latitude de $-0,54^{\circ}$. (c) Pôr do Sol sobre o reservatório Gabriel e Galán (Espanha), latitude $40^{\circ}$ e (d) Pôr da Lua sobre a cidade de Oslo (Noruega), latitude $60^{\circ}$.

norte, identificando locais no hemisfério sul enquanto que nas Figuras 6c e 6d as trajetórias estão inclinadas para o sul, identificando locais localizadas no hemisfério norte. Verificamos assim que a inclinação da trajetória identifica o hemisfério que a imagem do nascer/pôr do Sol/Lua foi registrada, no hemisfério sul a trajetória é inclinada para o norte como mostra também a Figura 5 e no hemisfério norte a trajetória é inclinada para o sul.

A medida experimental da latitude pode ser obtida medindo diretamente nas fotografias o ângulo $\phi$ usando 
um transferidor ou a partir da medida das distâncias horizontal $X$ e vertical $Z$ (Figura 5 b) e calculando a latitude por

$$
\phi= \pm \arctan |X / Z| .
$$

onde o sinal positivo deve ser usado para localidades no hemisfério norte e o sinal negativo para localidades no hemisfério sul.

A análise da Figura 6 permite estimar o valor das latitudes locais em cada caso utilizando a Equação 4: para o pôr do Sol no parque nacional de Kruger a latitude medida foi de $-22^{\circ}$. Para o pôr do Sol sobre o reservatório Gabriel e Galán a latitude medida foi de $41^{\circ}$ e para o pôr da Lua sobre a cidade de Oslo a latitude medida foi de $60^{\circ}$. Para o Eclipse total do Sol ocorrido próximo ao amanhecer em Palu a latitude é da ordem de $-1,0^{\circ}$. Esses valores concordam aproximadamente com as latitudes dos locais das fotografias.

\subsection{Observando em direções diferentes da leste-oeste}

Deve-se destacar que em algumas das fotografias pesquisadas as trajetórias não são retas, como nos casos mostrados na Figura 7. A Figura 7a apresenta uma sequência de imagens espaçadas de aproximadamente quatro minu- tos do eclipse total do Sol ocorrido em 01/08/2008 em Novosibirsk na Rússia [25]. A cena focaliza uma posição sobre o lago Ob. A Lua cobriu totalmente o disco solar às $17 \mathrm{~h} 45 \mathrm{~min}$ no horário local [26]. A latitude local é de $55^{\circ}$.

Já a Figura 7d apresenta uma série de exposições realizadas a cada cinco minutos do eclipse solar total observado em Chisamba (Zambia) [27]. Esse eclipse ocorreu em 21/06/2001 e seu apse aconteceu às 15h11min (horário local) [28]. A latitude local é de $-15^{\circ}$.

O desvio de uma trajetória retilínea observado nas trajetórias apresentadas na Figura 7 deve-se ao fato da direção do observador nas quais as fotografias foram realizadas não ser a direção leste-oeste, ou seja, o observador não olhava diretamente para o leste ou para o oeste. Quando o observador olha para leste ou para oeste a trajetória é uma reta como na Figura 5 b e nas fotografias apresentadas na Figura 6.

A simulação das trajetórias correspondentes às situações apresentadas nas Figuras 7a e 7d foram sobrepostas às figuras, os resultados são mostrados nas Figuras 7b e 7e. Para produzir as simulações, o primeiro passo é determinar para cada caso a declinação local na data do eclipse. Usando a Equação 3, para o eclipse de Novosibirsk ocorrido em $1^{\circ}$ de agosto temos $N=7 \times 30=210$,
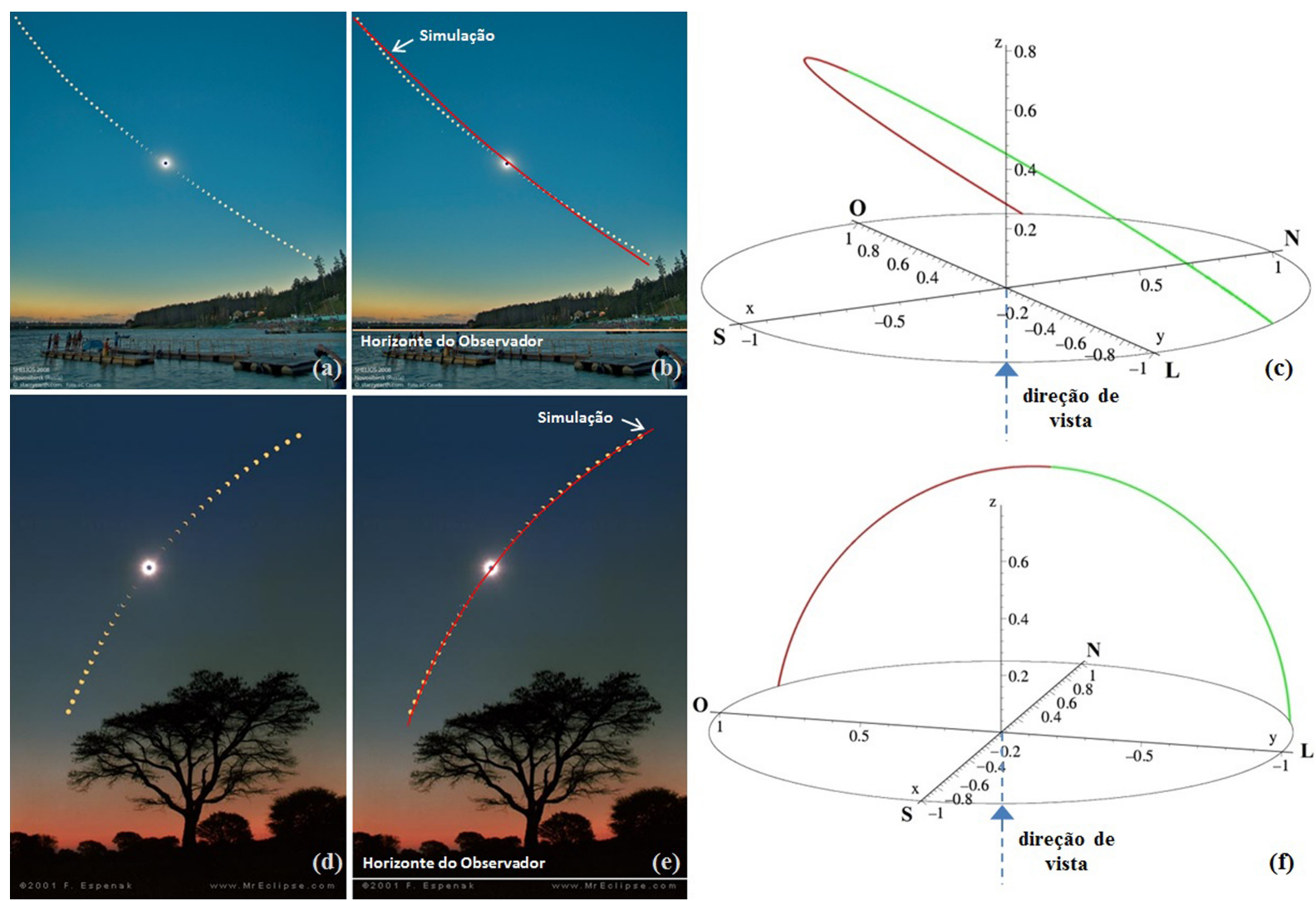

Figura 7: (a) Eclipse total do Sol em Novosibirsk (Rússia), latitude de $55^{\circ}$, visto em uma posição sobre o lago Ob, girada de $+299^{\circ}$ para leste do norte. (b) Simulação da trajetória sobreposta à figura. (c) Perspectiva 3D da trajetória. (d) Eclipse solar total em Chisamba (Zambia), latitude de $-15^{\circ}$. A direção de vista foi girada nesse caso de $+344^{\circ}$ para leste do norte. (e) Simulação da trajetória sobreposta à figura. (f) Perspectiva 3D da trajetória. 
logo a declinação nessa data é de aproximadamente $18^{\circ}$. Em Chisamba devemos notar que o eclipse ocorreu precisamente no dia do solstício de inverno do hemisfério sul, $21 / 06 / 2001(N=5 \times 30+20=170, \operatorname{logo}$ a declinação é $\delta=23,5^{\circ}$. As trajetórias no espaço foram determinadas em cada caso substituindo os valores das declinações e das latitudes locais ( $55^{\circ}$ para Novosibirsk e $-15^{\circ}$ para Chisamba) nas Equações 1 e 2, obtendo-se assim a altura e o azimute como função da hora solar $h$. Em seguida utilizando a transformação de coordenadas apresentada na Equação 9 do apêndice 1 as trajetórias são determinadas. Exemplos das trajetórias são mostrados nas Figuras $7 \mathrm{c}$ e $7 \mathrm{f}$.

O intervalo de tempo mostrado na Figuras 7a (Novosibirsk) corresponde a um total de 3h40min. Observe que temos 55 fotografias na sequência mostrada na figura. O espaço entre dois discos solares consecutivos é aproximadamente igual a um disco solar. Logo, pode-se considerar o tempo entre fotografias de 4 minutos, como veremos na seção 5.2. Portanto, a fotografia apresenta uma sequência que corresponde a um intervalo de tempo total de $3 \mathrm{~h} 40 \mathrm{~min}$ ( 55 fotografias $\times 220 \mathrm{~min}=3 \mathrm{~h} 40 \mathrm{~min}$ ), de aproximadamente $15 \mathrm{~h} 55 \mathrm{~min}$ até $19 \mathrm{~h} 35 \mathrm{~min}$. Vale destacar que nessa data o pôr do Sol ocorreu às 21h31min $[29]$.

A Figura 7d (Chisamba) mostra que o intervalo de tempo corresponde a um total de $2 \mathrm{~h} 40 \mathrm{~min}, 75 \mathrm{~min}$ (15 intervalos x 5min antes do eclipse) + 85min (17 intervalos x 5min depois do eclipse), portanto de $13 \mathrm{~h} 56 \mathrm{~min}$ a 16h36min.

De forma a simular o desvio em relação à trajetória reta, o plano de vista do observador foi girado de $\theta$ (sentido de norte para leste) até que a inclinação e a forma da curva na simulação ficassem semelhantes à apresentada na imagem. Uma rotação de $\theta=+90^{\circ}$ corresponde a um observador que olha precisamente para o leste e uma rotação de $\theta=+270^{\circ}$ corresponde a um observador que olha precisamente para oeste. Nesses casos as trajetórias simuladas são análogas às apresentadas nas Figuras 5b e 6.

As rotações determinadas foram de $+299^{\circ}$ para o eclipse ocorrido em Novosibirsk e $+344^{\circ}$ para o eclipse ocorrido em Chisamba. Utilizando-se esses valores as trajetórias simuladas, curvas vermelhas nas Figuras 7b e 7e, sobrepõe as trajetórias experimentais, Figuras 7a e 7d. As Figuras 7c e $7 \mathrm{f}$ apresentam as trajetórias simuladas em uma perspectiva $3 \mathrm{D}$, onde o plano do horizonte do observador foi inclinado de $12^{\circ}$ para melhor visualização. Portanto ângulos de vista diferentes conduzem a formas de trajetórias diferentes Nas Figuras 7c e 7f, em verde é apresentado o período do nascer do Sol até $12 \mathrm{~h}$ e em vermelho o período de $12 \mathrm{~h}$ até o pôr do Sol. A linha tracejada azul mostra a direção de vista que corresponde a direção aproximada que os fotógrafos direcionaram suas câmeras ao realizar as belas fotografias apresentadas na figura 7 .
Por fim, uma análise cuidadosa da Figura 6.c permite observar o movimento retrógrado da Lua. Outras fotografias mostram fenômenos semelhantes. Uma sobreposição de imagens do pôr do Sol e do pôr da Lua no equinócio da primavera (21/03/2008) em Figueres Espanha [30] e o sistema solar ascendendo sobre Fire Island, Nova York, EUA [31]. O apêndice 2 apresenta uma análise complementar da sobreposição dos movimentos do Sol e da Lua observado em [30].

\section{Projeção da imagem do Sol em uma parede utilizando um pequeno espelho}

A projeção da luz solar em uma parede distante com o auxílio de um pequeno espelho geralmente produz uma imagem nítida do disco solar [32]. O mesmo fenômeno ocorre quando a luz do Sol atravessa o espaço entre as folhas da copa de uma árvore, produzindo círculos no chão que representam também imagens do disco solar [11]. A projeção da imagem do Sol por uma pequena abertura é um artifício que permite a observação e o estudo com segurança da dinâmica do movimento do Sol no céu, da mesma forma que facilita a observação de eclipses solares [11].

O pequeno espelho funciona nas observações como análogo à abertura de uma câmera escura. Um estudo detalhado da situação foi realizado por Silveira e Axt [32].

O princípio da câmera escura pode assim ser utilizado para estimar a abertura angular do Sol e também, se acompanhamos o movimento da imagem projetada com o tempo que representa o movimento diurno do Sol no céu, podemos estimar a latitude local. Outro ponto importante é que a velocidade da imagem na parede tem relação direta com a rotação da Terra [33]. Portanto, os experimentos apresentados nas próximas seções podem ser excelentes recursos didáticos para o ensino diurno de astronomia.

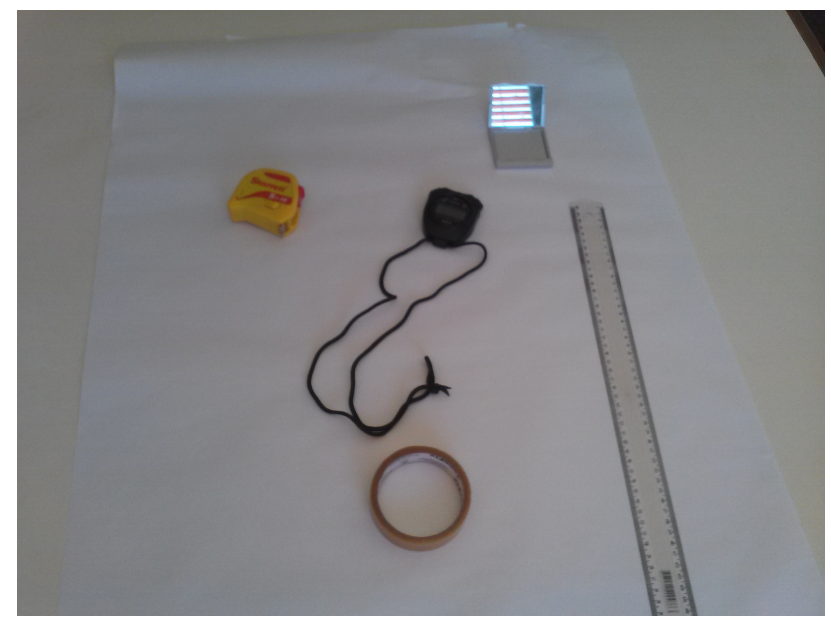

Figura 8: Aparato experimental. 


\section{Medidas usando a imagem do Sol}

Os experimentos da abertura angular do Sol e da medida da latitude local a partir da imagem projetada do Sol utilizando um pequeno espelho têm sido realizados na disciplina Universo, que compõe a grade curricular do segundo semestre de curso de Ciências Naturais da Universidade de Brasília. Os autores desse artigo, atuando por vários semestres como professor dessa disciplina, desenvolveram e aprimoraram os procedimentos experimentais aqui relatados. O experimento é uma oportunidade dos estudantes do período diurno analisarem o movimento de um astro no céu.

Antes de iniciar os experimentos os estudantes devem ser alertados para nunca olhar diretamente para o Sol, nem mesmo para o reflexo do astro através do espelho e também para não focar o reflexo do Sol nos olhos dos colegas.

Os materiais para realização das medidas são de fácil aquisição e baixo custo. Conforme a Figura 8, foram utilizados: pequeno espelho de bolso, trena, cronômetro, régua, fita adesiva e cartolina. Uma parede pode ser usada como anteparo.

É indicado usar um espelho quadrado ou retangular, ou uma máscara com esse formato que pode ser feita cobrindo parte do espelho, ao invés de um espelho redondo. Dessa forma pode-se mostrar que uma imagem circular do Sol é formada [32] independente do formato do espelho.

No nosso experimento é usado um pequeno espelho de bolso aproximadamente quadrado com $5 \mathrm{~cm}$ de lado. Esse espelho é composto por duas abas que permite posicionálo facilmente no chão de maneira a projetar a imagem do Sol no anteparo.

Usando um espelho com essas dimensões é recomendado que a distância entre a parede e o espelho seja maior que 10 metros, de forma a obter uma imagem nítida do Sol. Como sugestão, pode-se acompanhar os raios de luz que projetam a imagem na parede utilizando um anteparo (uma folha de papel A4, por exemplo). Se colocado logo à frente do espelho a imagem projetada no anteparo tem a forma retangular do espelho. À medida que o anteparo é afastado em direção a parede, a imagem adquire a forma do disco solar, sendo que quanto maior é a distância, mais nítida fica a borda da imagem projetada e maior é o seu diâmetro. Mas em compensação a luminosidade da imagem diminui com a distância.

A parede (anteparo) pode ser imaginada como o fundo de uma câmara escura. Assim, o espelho deve ser posicionado de forma que os raios refletidos fiquem aproximadamente perpendiculares à parede para evitar distorções.

A Figura 9 apresenta estudantes da disciplina Universo realizando algumas medidas. Observe que a imagem do Sol é bem visível, pois a parede fica na sombra. Assim recomendamos que, se possível, o anteparo fique na sombra para melhor visualização e também por motivos de conforto térmico.

Recomenda-se também atenção à previsão do tempo. $\mathrm{O}$ ideal é que o dia esteja ensolarado e com poucas nuvens, pois só é possível a realização de medidas quando o Sol está visível.

A atividade pode ser realizada com vários níveis de dificuldade que diferem em relação aos objetivos a serem alcançados. O experimento pode ser realizado em três etapas:

* Medida da abertura angular do Sol usando um triângulo

* Medida da abertura angular do Sol usando o tempo de trânsito da imagem

* Medida da latitude local

\subsection{Abertura angular do Sol medida por triângulo}

Uma medida possível a partir da imagem do Sol projetada em uma parede é determinar a abertura angular do Sol [32]. A Figura 10 apresenta o esboço da situação. Na parte superior da figura $\ell$ representa a distância TerraSol e $d$ o diâmetro do Sol. Na parte inferior da figura $L$
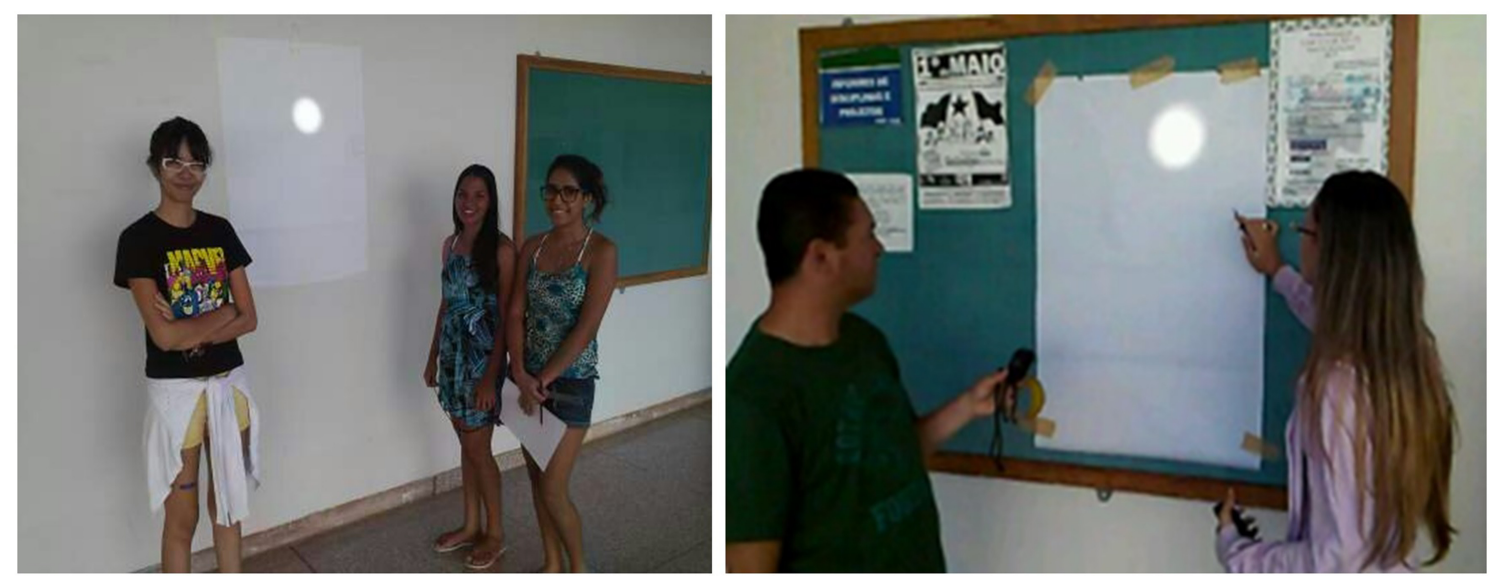

Figura 9: Estudantes realizando o experimento. 


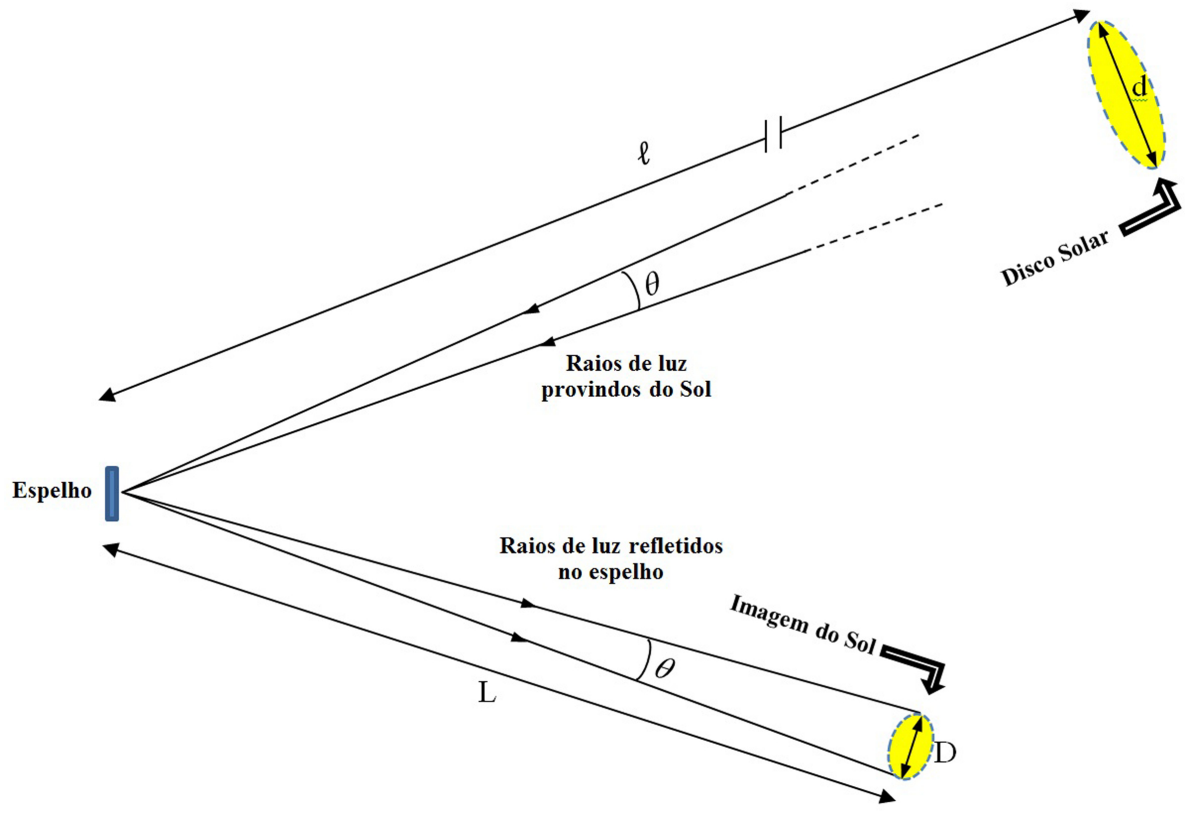

Figura 10: Imagem do Sol de diâmetro $D$ projetada por um pequeno espelho a uma distância $L$.

representa a distância da imagem projetada ao espelho e $D$ o diâmetro da imagem do Sol projetada na parede.

Os raios de luz provenientes do Sol ao refletir no espelho produzem a bela imagem do Sol mostrada na Figura 9, desde que as dimensões do espelho sejam muito menores que $L$ [32]. Podemos determinar a abertura angular do Sol $\theta$ utilizando o esboço dos raios de luz apresentado na Figura 10 como

$$
\theta=d / \ell=D / L
$$

desde que a abertura angular $\theta$ seja pequena, que é o caso para o Sol como objeto.

Na Figura 9 os estudantes projetaram o disco solar na parede e estão avaliando seu diâmetro. Nessa medida o espelho foi posicionado a $L=(18,0 \pm 0,1) \mathrm{m}$ da parede que serviu como anteparo. O diâmetro $D$ da imagem do Sol projetada na parede medido foi de $(17 \pm 1) \mathrm{cm}$.

Calculando a abertura angular do Sol, a Equação 5 conduz a $\theta=D / L=0,17 / 18,0=0,0094 \mathrm{rad}$ que transformado para graus assume o valor $\theta=0,0094 \times$ $\frac{180^{\circ}}{\pi}=0,54^{\circ}$.

No artigo vamos utilizar o método apresentado na Ref. [34] para determinar as incertezas experimentais. O uso do método para o cálculo da incerteza experimental relativa à Equação 4 é apresentado na Equação 8. A aplicação do método para situação acima conduz ao resultado $\theta=(0,54 \pm 0,04)^{\circ}$. O apêndice 3 apresenta os cálculos para esse caso particular. O valor obtido para a abertura angular do Sol concorda com valores da literatura [20][33].

A abertura angular do Sol varia ao longo do ano com a distância Terra-Sol $\ell$, que assume o valor mínimo de $147,1 \times 10^{9} \mathrm{~m}$ no afélio e o valor máximo de $152,1 \times 10^{9}$ $\mathrm{m}$ no periélio. $\mathrm{O}$ afélio acontece nos primeiros dias de julho enquanto o periélio ocorre nos primeiros dias de janeiro [35], aproximadamente duas semanas depois dos solstícios. Tomando a média desses valores e considerando o intervalo obtêm-se $\ell=(149,6 \pm 2,5) \times 10^{9} \mathrm{~m}$ para distância média Terra-Sol. Assim a abertura angular do Sol calculada a partir da Equação 5, considerando o diâmetro do Sol igual a $1,392 \times 10^{9} \mathrm{~m}$, varia ao longo do ano no intervalo $(0,53 \pm 0,01)^{\circ}$.

Como atividade complementar pode ser solicitada a determinação do diâmetro do Sol supondo conhecida a distância média Terra-Sol $\ell$. A Equação 5 permite expressar o diâmetro do Sol como

$$
d=D / L \ell
$$

Assim nesse experimento o diâmetro $d$ do Sol vale

$$
d=\frac{0,17}{18,0} \times 149,6 \times 10^{9}=1,4 \times 10^{9} \mathrm{~m} .
$$

com incerteza experimental de $0,1 \times 10^{9} \mathrm{~m}$. Uma comparação pode ser realizada com o diâmetro médio do Sol $d=1,392 \times 10^{9} \mathrm{~m}$, que está dentro da faixa de incerteza experimental.

\subsection{Abertura angular do Sol medida pelo tempo de trânsito da imagem $t_{D}$}

A partir da medida do tempo $t_{D}$ para a imagem do Sol percorrer a distância correspondente a um diâmetro $D$ de sua própria imagem, uma nova estimativa da abertura angular pode ser realizada [33].

Para realizar essa medida é marcada a posição da imagem e nesse momento inicia-se a contagem do tempo de trânsito $t_{D}$. A medida do tempo é realizada enquanto a imagem se move por um diâmetro. A cronometragem é 
interrompida assim que um diâmetro solar é percorrido, conforme a Figura 11.

Em aproximadamente 24 horas (86400 segundos) o Sol varre um ângulo de $360^{\circ}$. Logo no tempo $t_{D}$ o ângulo varrido será a abertura angular. Assim, se a medida do tempo de trânsito $t_{D}$ é realizada em segundos, a abertura angular é dada por

$$
\theta=360^{\circ} t_{D} / 86400
$$

Na Figura 9 os estudantes estão medindo o tempo de trânsito $t_{D}$ para o Sol percorrer a distância $D$ correspondente ao diâmetro de sua imagem na parede. O resultado para o tempo de trânsito do Sol sobre o seu diâmetro foi de 2 minutos e 10 segundos, ou seja, $(130 \pm 10)$ s. Não é possível obter maior precisão na medida do tempo já que as imagens do Sol no anteparo têm bordas ligeiramente borradas, o que dificulta determinar quando o Sol percorre exatamente um diâmetro. Substituindo esse valor na Equação 7 obtemos para abertura angular do Sol o valor

$$
\theta=(0,54 \pm 0,04)^{\circ}
$$

Um resultado aproximado para a abertura angular do Sol também pode ser obtido pela análise das fotografias apresentadas na Ref. [30]. Nessa fotografia o tempo entre as imagens da sequência é de 4 minutos. Nesse tempo o Sol percorre uma distância aproximada de 2 diâmetros solares. Com esses dados a Equação 7 dá o resultado de 0,5 para a abertura angular do Sol. Veja também o apêndice 2 .

\subsection{Medida da latitude local}

A medida da latitude é realizada de forma simples utilizando uma linha inclinada que mostra a trajetória do Sol, conforme mostrado na Figura 12 que esboça a montagem experimental.

Ao lado da imagem do disco solar pode ser pendurado um fio de prumo com uma fita adesiva para definir a direção vertical.
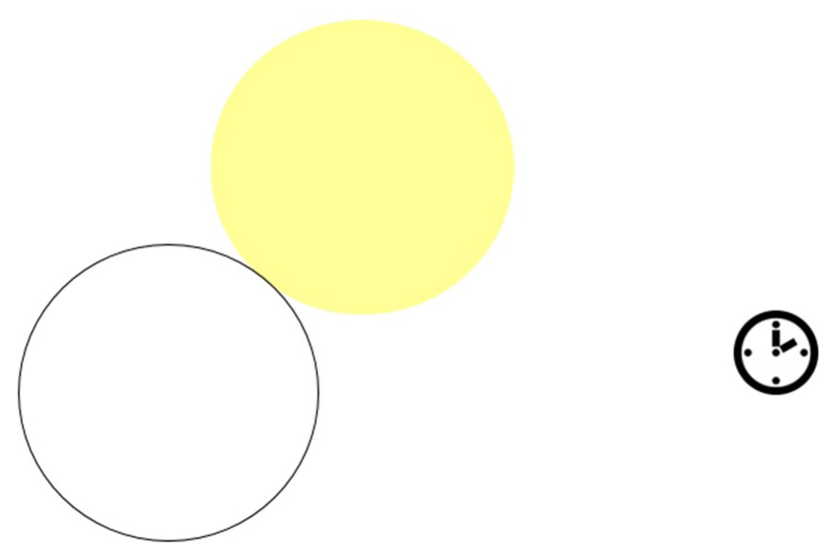

Figura 11: Instante em que a cronometragem do tempo de trânsito de um diâmetro da imagem do Sol deve ser interrompida.

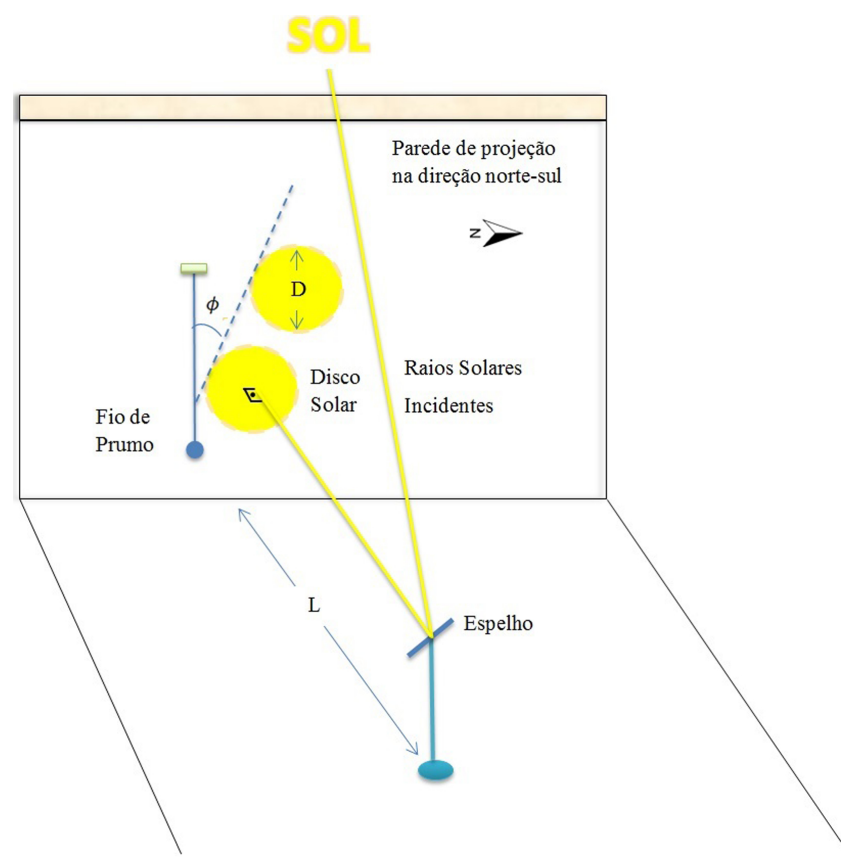

Figura 12: Montagem experimental.

A avaliação da trajetória do disco solar na parede reproduz uma situação semelhante a apresentada na Figura 5b. Essa figura mostra que para realizar a medida da latitude é necessário um anteparo paralelo à direção norte-sul. Como nem sempre as paredes estão na direção norte-sul, recomenda-se o uso de um mural ou similar. O norte verdadeiro só precisa ser determinado uma vez pelo professor, podendo utilizar a internet, o Google Earth [36], um aparelho de GPS, a sombra de um gnomo ao meio dia [37] ou mesmo uma bússola se conhecida a declinação magnética local.

A inclinação da direção da linha com a vertical, definida pelo fio de prumo, representa o valor experimental da latitude. A medida da largura horizontal $X$ e da altura vertical $Z$ permitem determinar a inclinação da trajetória projetada com o uso de um transferidor ou através da Equação 4. Em seguida o valor pode ser comparado ao valor real da latitude no local do experimento com o auxílio do software Google Earth [36], por exemplo.

No caso de ser usada a Equação 4 a incerteza da latitude é devido às incertezas experimentais nas medidas de X e Z. A propagação de incertezas, usando novamente o interessante método apresentado na Ref. [34], nos dá que:

$$
\Delta \phi=\sqrt{\overline{\Delta X}^{2}+\overline{\Delta Z}^{2}}
$$

onde $\overline{\Delta X}=\arctan \left|\frac{X+\Delta X}{Z}\right|-\phi$ e $\overline{\Delta Z}=\arctan \left|\frac{X}{Z+\Delta Z}\right|-$ $\phi$

Por exemplo, para obter o valor de uma incerteza $\Delta \phi$ típica vamos considerar valores factíveis experimentalmente de $X$ e $Z$ da ordem de $50 \mathrm{~cm}$ e das incertezas nas medidas experimentais dessas grandezas $\Delta X$ e $\Delta Z$ como $1 \mathrm{~cm}$. Não é possível obter precisão de milímetros já que 
as imagens do Sol no anteparo têm bordas ligeiramente borradas, o que não permite medidas mais precisas. A Equação 8 fornece como resultado uma incerteza experimental para latitude menor do que $1^{\circ}$. Deve-se destacar que para um bom experimentalista pode-se alcançar uma incerteza de alguns décimos de graus.

Medidas experimentais foram realizadas nas cidades de Brasília-DF e em Santarém-PA, em locais com latitude respectivamente de $-15,6^{\circ}$ e $-2,4^{\circ}$, segundo dados apresentados no software Google Earth [36].

Para a medida realizada em Brasília a vertical dada pelo fio de prumo e a trajetória do disco solar estão destacadas no esboço da situação apresentado na Figura 13. O valor da latitude medido foi de $(-15 \pm 1)^{\circ}$. A incerteza experimental foi estimada a partir da Equação 8. De forma geral os valores de latitude determinados por vários grupos de estudantes para esse experimento se encontram na faixa entre $-17^{\circ} \mathrm{e}-15^{\circ}$.

Uma forma de medir a latitude com maior precisão é fazer a sobreposição de uma sequência de fotografias das imagens do disco solar no anteparo utilizando uma câmera digital padrão [38], seguindo a ideia das sequências apresentadas na Figura 6. A Figura 14 apresenta a sobreposição de imagens de medidas realizadas em Santarém no estado do Pará utilizando uma câmera digital (Panasonic DMC-FH6 de 14 Mega Pixels) colocada sobre um tripé.

No local da medida a latitude é de $-2,4^{\circ}[36]$. O intervalo de tempo representado é de 5 minutos, apenas a primeira e a última imagem de uma sequência de cinco fotografias registradas foram apresentadas na Figura 14 para maior clareza. A distância do espelho à parede medida foi de $L=10 \mathrm{~m}$. A altura do triângulo destacado na figura é de $Z=403 \pm 2$ pixels e a base do triângulo $X=16 \pm 2$ pixels.

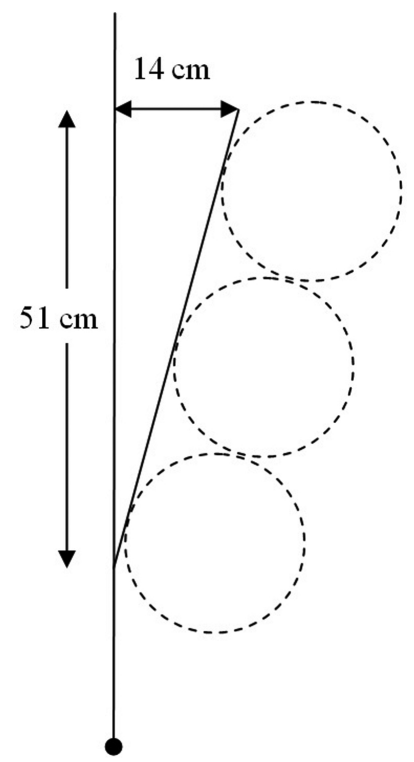

Figura 13: Esboço de medida típica da latitude em Brasília.

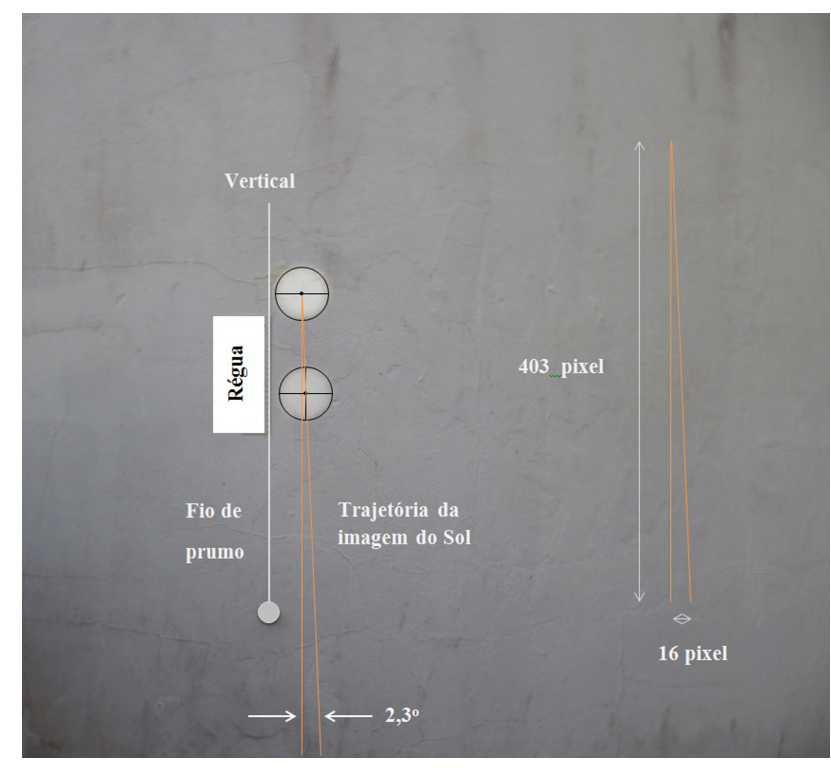

Figura 14: Sobreposição de imagens do disco solar para medida realizada em Santarém, no estado do Pará. A latitude medida foi de $(-2,3 \pm 0,3)^{\circ}$.

A análise da Figura 14 mostra que o disco solar descreve uma trajetória inclinada em relação à vertical de $(-2,3 \pm 0,3)^{\circ}$. A incerteza experimental foi estimada a partir da Equação 8. Os resultados estão de acordo com a latitude local de Santarém.

\section{Conclusão}

Os desafios do ensino de astronomia têm relação direta com a formação dos educadores que atuam na área e com a disponibilidade de recursos materiais e didáticos. Nossa proposta de atividade para observação diurna do céu avalia o movimento do Sol no céu a partir da projeção de sua imagem por um pequeno espelho. Esse experimento pode ser adaptado para o uso em diversos níveis de ensino e de maneira interdisciplinar entre ciências naturais, geografia, matemática e física. Além de permitir a compreensão do movimento de um astro no céu, o experimento possibilita o cálculo de grandezas astronômicas importantes como a medida da abertura angular do Sol, o cálculo do diâmetro do Sol e a medida da latitude geográfica local.

O experimento é uma oportunidade de estudantes do período diurno analisarem o movimento de um astro no céu experimentalmente.

Para as medidas realizadas em Brasília, os procedimentos experimentais conduzem aos seguintes resultados: a abertura angular do Sol determinada através da Equação 5 é $(0,54 \pm 0,04)^{\circ}$. O diâmetro $d$ do Sol estimado a partir da Equação 6 vale $(1,4 \pm 0,1) \times 10^{9} \mathrm{~m}$. A Equação 7 conduz ao valor de $(0,54 \pm 0,04)^{\circ}$ para abertura angular do Sol, concordando com o resultado determinado a partir da Equação 5. Esses valores estão de acordo com dados da literatura. 
Medidas experimentais da latitude foram realizadas nas cidades de Brasília-DF e em Santarém-PA. Os resultados obtidos foram $(-15 \pm 1)^{\circ}$ e $(-2,3 \pm 0,3)^{\circ}$, que estão de acordo com a latitude dessas localidades [36].

Os procedimentos experimentais apresentados são válidos para o estudo do movimento diurno do Sol que apresenta semelhanças com o movimento de outras estrelas.

Finalmente através da análise de fotografias do movimento do Sol e da Lua capturadas na Internet é possível obter resultados relevantes como a latitude local e a velocidade de revolução da Lua ao redor da Terra. Os resultados dos experimentos apresentam precisão e são simples de serem aplicados para diversos níveis de ensino com adaptações apropriadas realizadas pelo professor.

\section{Agradecimentos}

Os autores agradecem aos estudantes que gentilmente permitiram utilizar suas imagens nesse artigo e aos fotógrafos em disponibilizar através de licenças Creative Commons [39] as belas imagens utilizadas na produção do artigo. Agradecem também ao fotógrafo Fred Espenak por autorizar o uso da fotografia Eclipse Sequence Over Africa de 2001. Finalmente agradecem o apoio dos técnicos do laboratório didático de Geociências e Física da Faculdade UnB Planaltina.

\section{Material Suplementar}

O seguinte material suplementar está disponível online: Apêndice 1

Apêndice 2

Apêndice 3

\section{Referências}

[1] A.L.D. Fróes, Revista Brasileira de Ensino de Física 36, 3504 (2014).

[2] M.R.B. Almeida, O Conhecimento dos Alunos Sobre Astronomia ao Final do Ensino Médio. Trabalho de Conclusão de Curso, FUP/UnB (2012), disponível em http://bdm.unb.br/bitstream/10483/4106/1/ 2012_MarceloRubensBragadeAlmeida.pdf acesso em $14 / 12 / 2016$.

[3] R. Langhi e R. Nardi, Revista Brasileira de Ensino de Física 31, 4402 (2009).

[4] L.M. Darroz e F.M.T. Santos, Caderno Brasileiro de Ensino de Física 30, 104 (2013).

[5] Brasil, Secretaria de Educação Fundamental, Parâmetros Curriculares Nacionais: Ciências Naturais (MEC/SEF, Brasília, 1998).

[6] R. Langhi e R. Nardi, Caderno Brasileiro de Ensino de Física 24, 87 (2007).

[7] AEBescola. Eventos de Divulgação Científica - SBPC Jovem e Semana Nacional de Ciência e Tecnologia. Disponível em http://aebescola.aeb.gov.br/ index.php/eventos Jornada Espacial. Disponível em http://aebescola.aeb.gov.br/index.php/jornada
Olimpíada Brasileira de Astronomia e Astronáutica. Disponível em http://aebescola.aeb.gov.br/ index.php/8-destaque/19-oba Repositório de materiais didáticos e outros. Disponível em http: //aebescola.aeb.gov.br/index.php/repositorio Repositório de Apresentações. Disponível em http://aebescola.aeb.gov.br/index.php/ repositorio/apresentacoes, acesso em 15/02/2016.

[8] J.S. Pereira, Astronomia no Ensino Médio: Oficinas de Astronomia. Trabalho de Conclusão de Curso, UCB (2006). Disponível em https://www.ucb.br/sites/100/118/TCC/2\%C2\% BA2006/TCCJeffersondeSousaPereira.pdf. Acesso em $14 / 12 / 2016$.

[9] S.S.M. Azevedo, M.C.R. Pessanha, D.U.S. Schramm e M.O. Souza, Revista Brasileira de Ensino de Física 35, 2403 (2013).

[10] I.A.F.S. Pereira, Medida da Latitude Geográfica Local pela Posição do Sol: Procedimento Prático para Aula de Astronomia Diurna. Trabalho de Conclusão de Curso, FUP/UnB (2009).

[11] F.L. Silveira e R. Axt, Caderno Brasileiro de Ensino de Física 24, 353 (2007).

[12] F.S. Silva, F. Catelli e O. Giovannini, Caderno Brasileiro de Ensino de Física 27, 7 (2010).

[13] D.S. Leão, Física na Escola 12(2), 42 (2011).

[14] A.G. Trogello, M.C.D. Neves e S.C.R. Silva, Caderno Brasileiro de Ensino de Física 32, 223 (2015).

[15] A. Vechi, A.F. Brito, D.B. Valemtim, M.E. Gozzi, A.R. Sampaio e R.C. Viscovini, Revista Brasileira de Ensino de Física 35, 2505 (2013).

[16] Disponível em http://aebescola.aeb.gov.br/ downloads/material/mao_na_massa_oficinas.pdf acesso em 16/02/2017.

[17] K. Oliveira e M.F. Saraiva, Astronomia e Astrofísica (Livraria da Física, São Paulo, 2014).

[18] J.C. Casado, Delta del Okavango, Botswana. 2004. Disponível em https://www.flickr.com/photos/ starryearth/15368580229/, acesso em 17/02/2017.

[19] Disponível em https://pt.wikipedia.org/wiki/ Sistema_horizontal_de_coordenadas, acesso em 14/12/2016.

[20] B. Santiago e A. Salviano, Astronomia Geodésica: Posicionamento pelas Estrelas. Disponível em http://www if .ufrgs.br/oei/santiago/fis2005/livro_v1.pdf, acesso em 14/12/2016.

[21] J.C. Casado, Parque Nacional Kruger, África do Sul. 2014. Disponível em https://www.flickr.com/photos/ starryearth/15309263071/ acesso em 17/02/2017.

[22] J.C. Casado, Kotapulu_phases. 2016. Disponível em https://www.flickr.com/photos/starryearth/ 27412622445/, acesso em 17/02/2017.

[23] J.C. Casado, Embalse de Gabriel y Galán, España. 2009. Disponível em https://www.flickr.com/photos/ starryearth/15556210262/, acesso em 17/02/2017.

[24] G. Soponyai, Moonset in Oslo. 2015. Disponível em https://www.flickr.com/photos/vanamonde81/ 17207852031/, acesso em 17/02/2017.

[25] J.C. Casado, Novosibirsk, Rusia. 2008. Disponível em https://www.flickr.com/photos/starryearth/ 14761282906/, acesso em 17/02/2017. 
[26] Disponível em https://www.timeanddate.com/ eclipse/in/russia/novosibirsk?iso=20080801 acesso em 14/12/2016.

[27] F. Espenak, Eclipse Sequence Over Africa. 2001. Disponível em http://www.mreclipse.com/SEphoto/ TSE2001/image/T01-05w. JPG acesso em 11/04/2017.

[28] Disponível em https://www.fourmilab.ch/images/ eclipse_2001/, acesso em 14/12/2016.

[29] Disponível em https://www.timeanddate.com/sun/ russia/novosibirsk?month=8\&year $=2008$, acesso em $17 / 02 / 2017$.

[30] J.C. Casado, Sunset and Moonset at 2008 Equinox. 2008. Disponível em http://twanight.org/newTWAN/photos. asp? ID=3001347, acesso em 17/02/2017.

[31] L. Landolfi, Solar system rising over Fire Island. 2005. Disponível em https://apod.nasa.gov/apod/ ap050503.html, acesso em 17/02/2017.

[32] F.L. Silveira e R. Axt, Caderno Brasileiro de Ensino de Física 18, 246 (2001).

[33] P.G. Hewitt, Física Conceitual (Bookman, Porto Alegre, 2015).

[34] P. Lima Junior e F.L. Silveira, Revista Brasileira de Ensino de Física 33, 2303 (2011)

[35] Disponível em http://astro.if.ufrgs.br/estacoes. html, acesso em 14/12/2016.

[36] Disponível em https://www.google.com.br/intl/ptBR/earth/, acesso em 14/12/2016.

[37] Disponível em http://astro.if.ufrgs.br/tempo/mas. htm, acesso em 14/12/2016.

[38] S. Gil, H.D. Reisin and E.E. Rodríguez, Am. J. Phys 74, 768 (2006)

[39] Disponível em https://creativecommons.org/ licenses/by-nc/2.0/, acesso em 17/02/2017. 